\title{
Wedge SPlitTing TeSt: DisPlacement FiELd ANALYSIS BY Multi-Parameter Fracture Mechanics
}

\author{
Stanislav SEITL ${ }^{1,2}$, Petr MIARKA ${ }^{1,2}$, Vladimir RUZICKA ${ }^{2}$, Lucie MALIKOVA ${ }^{1}$, Ildiko MERTA ${ }^{3}$ \\ ${ }^{1}$ Institute of Physics of Materials, Academy of Sciences of the Czech Republic, \\ Zizkova 22, 61662 Brno Czech Republic \\ ${ }^{2}$ Faculty of Civil Engineering, Brno University of Technology, \\ Veveř́ 331/95, 60200 Brno, Czech Republic \\ ${ }^{3}$ Research Centre of Building Materials, Material Technology, and Fire Safety Science, Faculty of Civil Engineering, \\ Technical University of Vienna, Austria
}

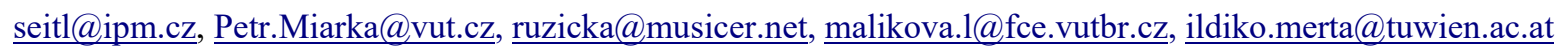

DOI: $10.31490 /$ tces-2018-0016

\begin{abstract}
Multi-parameter fracture mechanics is nowadays quite extensively applied when cracked structures/specimens are investigated. The reason was that it has been shown that it can be helpful and bring results that are more accurate when for describing of fracture processes a larger region around the crack tip is used. This can be typical for material like concrete or other materials with quasi-brittle behaviour. Various relative crack length configurations were chosen in order to investigate the importance of the higher-order terms of the Williams expansion (WE) on the crack-tip stress field distribution in Wedge splitting test specimen. The higher-order terms were calculated by means of the over-deterministic method from displacements of nodes around the crack tip obtained by a finite element analysis in different radial distances from the crack tip. The effect of the constraint level (second member of WE) was investigated. Although the third and higher terms of the Williams series are very often neglected, their influence on the opening stress values was investigated and discussed.
\end{abstract}

\section{Keywords}

WST, ODM, Williams series, FEM, displacement, fracture mechanics.

\section{Introduction}

The wedge splitting test (WST), introduced by Linsbauer and Tschegg [1], [2] and later developed by Brühwiler and Wittmann [3], is an interesting experimental method since it does not require sophisticated testing equipment to achieve a quasi-static (stable) fracture process. An ordinary electromechanical testing machine with a constant actuator displacement rate can be used and no sophisticated test stability control apparatus (i.e. closed loop control unit with e.g. crack tip opening displacement as a feedback signal) is necessary. The test is nowadays widely used by researchers see e.g. Zimmerman and Lehký [4] - for two classes of cement based concrete C 40/50 and C 50/60, Seitl et al [5] - for foam concrete, Merta et al [6]concrete with natural fibers, Walter [7] - for concrete-steel interface, Korte et al for self-compacting concrete [8][9][10] and for vibrated concrete [9][11], ASTM 122196 [12] - for steel, etc.

The test specimens can be prepared either from the cube Merta [13] or cylindrical specimens by Seitl [14] casted into standardized moulds, or as prismatic or cylindrical specimens taken from existing structures by sawing or core-drilling, respectively. The paper by Sobek [15] is focused on the stress field analysis (especially the shape functions) in WST for approximation of the stress and displacement fields in cracked specimens in two variants of plane problem - the plane stress and the plane strain condition.

The aim of this contribution is to introduce displacement field in specimen for WST. The various relative crack lengths (from small $a / W=0.1$ up to long $a / W$ $=0.8$ ) and quantify influence of boundary conditions on the displacement field in the vicinity of the crack tip for the constant value of the first member of Williams expansion series (stress intensity factor values equals 1 $\mathrm{MPa} \mathrm{m}^{1 / 2}$ ). For simulation of stress/displacements fields in WST, the finite element method (FEM) was used.

\section{Theoretical Background}


In the following subchapters description of the Williams [16] stress field near the crack tip and an over deterministic method is introduced in next subchapter.

The crack-tip stress/displacement field in this work is approximated via the Williams expansion (WE), particular relations can be written in the form:

$\sigma_{i, j}=\sum_{n=1}^{\infty} \frac{n}{2} r^{\frac{n}{2}} A_{n} f_{\sigma_{i, j}}(\theta, n)$, where $i, j \in\{x, y\}$

More important is expression for displacement equations:

$u_{i}=\sum_{n=1}^{\infty} r^{\frac{n}{2}} A_{n} f_{i}^{u}(\theta, n, E, \eta)$, where $\mathrm{i} \in\{\mathrm{x}, \mathrm{y}\}$

Displacement field is obtain from analysis done in software ANSYS, materials input properties $(E, v)$ are given for each material from measurement.

\section{Over-deterministic method}

The over-deterministic method (ODM) was proposed by Ayatollahi and Nejahi [17] and provides accurate results of the WE coefficients, it has been chosen with regard to the previous experience of the authors. Its largest advantage is that it requires only the knowledge of the nodal displacement solution around the crack tip. Thus, the displacements together with the polar coordinates of a selected set of nodes defined at a particular radial distance around the crack tip serve as an input for Eq. 2 and the only variables $A_{\mathrm{n}}$ are calculated. At least the one condition that has to be fulfilled should be mentioned: a minimum of $N / 2+1$ nodes are needed to be able to determine $N$ coefficients see e.g. in [17] and [18]. The influence of rounding is mentioned by Ruzicka et al [19].

\section{Modelling in FEM Software}

\subsection{Geometry of WST}

Geometry of investigated WST specimen was width $(S) \times$ height $(W)$, particularly $75 \mathrm{~mm} \times 150 \mathrm{~mm}$ [13], notch was modelled as a crack (i.e. with zero width). The material for upper part can be made from various kinds of marble [20] or steel [1]. To provide accurate results the upper part was modelled as a steel plate [13] and steel part for forces application and a bottom part (mentioned as steel support) were modelled with dimensions $60 \mathrm{~mm} \times 20 \mathrm{~mm}, 10 \mathrm{~mm}$ $\times 10 \mathrm{~mm}, 5 \mathrm{~mm} \times 10 \mathrm{~mm}$, respectively. The Model's geometry and boundary conditions are shown in Fig. 1. Sketch of symmetrical half is rotated by $-90^{\circ}$ against the experimental performance due to crack tip with origin at global Cartesian coordination origin.

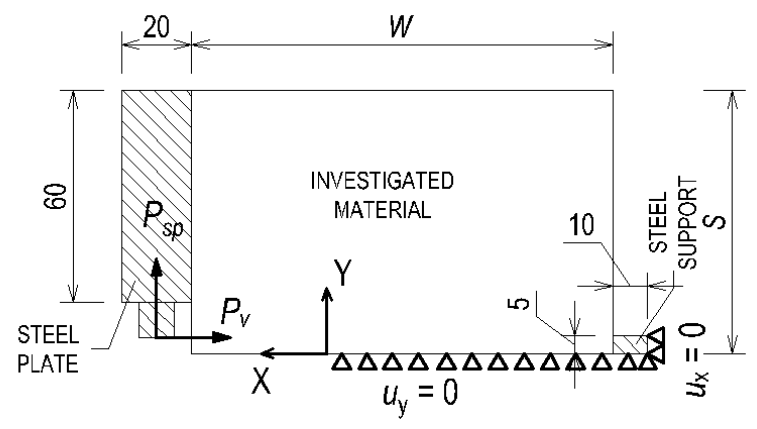

Fig. 1: Dimensions of studied geometry, symmetric half rotated by $-90^{\circ}$.

The numerical model was loaded with two forces simulating the induced displacement of the wedge into the specimen $P_{\mathrm{v}}$ (vertical direction) and $P_{\mathrm{sp}}$ (horizontal/splitting force). The vertical force $P_{\mathrm{v}}$ can be expressed as follows:

$P_{\mathrm{v}}=\frac{1}{2} P_{\mathrm{sp}} 2 \tan \left(\alpha_{\mathrm{w}}\right)$,

where $\alpha_{\mathrm{w}}=19.2^{\circ}$ represents wedge angle [13].

\subsection{Numerical Model}

The numerical model was created in a finite element software (FEM) Ansys 17.2 [21] as a plane symmetric 2D with the plane strain boundary conditions. Studied model was meshed with element type PLANE183 and command KSCON was applied to take into account the crack singularity. A linear elastic material model was used with input parameters: Young's modulus and Poisson's ratio. For the investigated material like concrete) material's constants were selected $E=30 \mathrm{GPa}$ and $v=0.2$, whereas $E=210 \mathrm{GPa}$ and $v=0.3$ for the steel frame.

Half model's boundary conditions are shown in Fig. 2, note that the numerical model is rotated by $90^{\circ}$ in comparison to the testing reality, due to more accurate results of nodal displacements when the crack tip is coincident with the origin of the global Cartesian coordinate system.

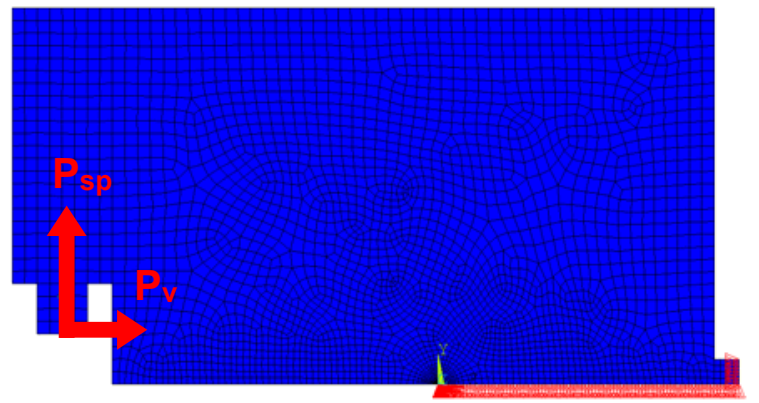

Fig. 2: Example of the symmetric half of WST specimen as numerical model rotated by $-90^{\circ}$ with used boundary conditions (arrows is applied force and triangles are boundary conditions).

In Fig. 3, detail in the vicinity of crack tip and selected nodes considered for displacements evaluation in radial distance $r=1 ; 2 ; 3 ; 4$ and $5 \mathrm{~mm}$ are shown. For ODM 
analysis the values from nodes in distance $r=1,3,5 \mathrm{~mm}$ were used.

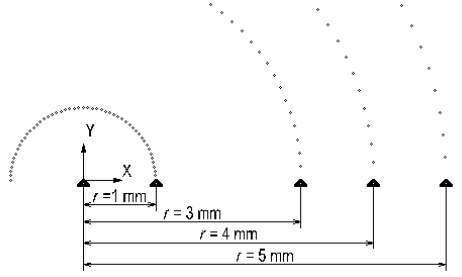

Fig. 3: Detail in the vicinity of crack tip and selected nodes considered for displacements evaluation in radial distance $1 ; 3 ; 4$ and $5 \mathrm{~mm}$.

The values of forces used in numerical simulation were chosen for all relative crack lengths $\alpha$ to produce the same value of the stress intensity factor (SIF). The SIF values were calculated by means of KCALC command in software ANSYS. The numerical results were compared to results in literature [22] and [23]. For this study, $K_{I}$ was chosen as $1 \mathrm{MPam}^{1 / 2}$ to provide better comparison of changes in the displacement field near the crack tip. The applied values of forces for selected relative crack lengths are mentioned in Tab. 1.

Tab. 1: Overview of applied forces for given relative crack length used for numerical analysis.

\begin{tabular}{|c|c|c|c|c|}
\hline$\alpha[-]$ & 0.1 & 0.2 & 0.3 & 0.4 \\
\hline $\boldsymbol{P}_{\mathrm{v}}[\mathbf{N}]$ & 30.42 & 23.65 & 18.65 & 14.22 \\
\hline $\boldsymbol{\alpha}[-]$ & 0.5 & 0.6 & 0.7 & 0.8 \\
\hline $\boldsymbol{P}_{\mathrm{v}}[\mathbf{N}]$ & 10.20 & 6.63 & 3.69 & 1.53 \\
\hline
\end{tabular}

These forces generate values of $T$-stress (second term related to $A_{2}$ ) as presented in Tab. 2.

Tab. 2: $T$-stress values and equivalent values of $A_{2}$ for given relative crack length used for numerical analysis generated by forces mentioned in Tab. 1.

\begin{tabular}{|c|c|c|c|c|}
\hline $\boldsymbol{\alpha}[-]$ & 0.1 & 0.2 & 0.3 & 0.4 \\
\hline $\begin{array}{c}\boldsymbol{T} \\
{[\mathbf{M P a}]}\end{array}$ & 4.24 & 5.22 & 5.60 & 5.75 \\
\hline $\boldsymbol{A}_{\mathbf{2}}[]$ & 1.06 & 1.30 & 1.40 & 1.44 \\
\hline $\boldsymbol{\alpha}[-]$ & 0.5 & 0.6 & 0.7 & 0.8 \\
\hline $\begin{array}{c}\boldsymbol{T} \\
{[\mathbf{M P a}]}\end{array}$ & 5.74 & 5.65 & 5.64 & 5.91 \\
\hline $\boldsymbol{A}_{\mathbf{2}}[\mathbf{]}$ & 1.43 & 1.41 & 1.41 & 1.48 \\
\hline
\end{tabular}

\section{Results and Discussion}

\subsection{Results from FEM}

The results of nodal displacement from the numerical analysis were used as an input parameter for the ODM method. The nodal displacements were generated for $\alpha=<0.1 \div 0.8>$ and for the radial distance from the crack tip $r=\{1 ; 3 ; 5\} \mathrm{mm}$. The example of nodal displacements generated by the FE model are presented in Fig. 4 and Fig. 5 .

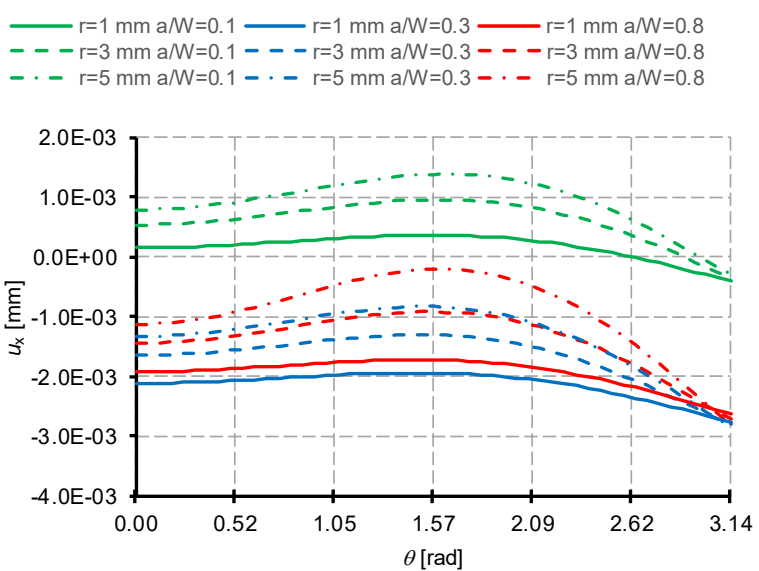

Fig. 4: Nodal displacements $u_{\mathrm{x}}$ generated via FE software for the relative crack length $\alpha=0.1,0.3$ and 0.8 in radial distance $r=1$, 3 and $5 \mathrm{~mm}$.

The nodal displacements $u_{x}$ as presented in Fig. 4. The plot for different $\mathrm{a} / \mathrm{W}=0.1-0.8$ has increasing values for long crack and it is caused by reduced stiffness of the specimen as the relative notch length and radial distance increases.

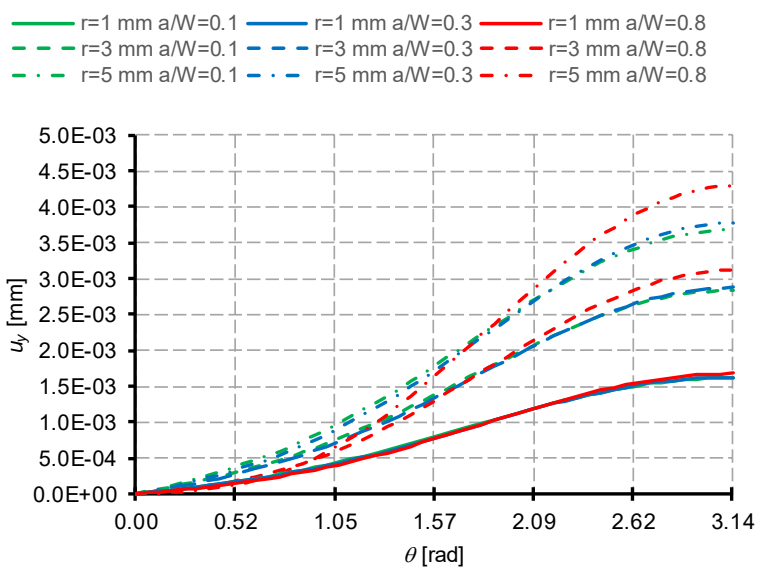

Fig. 5: Nodal displacements $u_{\mathrm{y}}$ generated via FE software for the relative crack length $\alpha=0.1,0.3$ and 0.8 in radial distance $r=1$, 3 and $5 \mathrm{~mm}$.

The nodal displacement $u_{\mathrm{y}}$ is shown in Fig. 5. The values are identical for all studied relative crack lengths in radial distance $r=1 \mathrm{~mm}$, where the $u_{\mathrm{y}}$ opens the specimen in mode I deformation very near of crack tip and stress is mathematically going to infinity. This agrees with the assumption of loading the specimen with forces producing $K_{\mathrm{I}}=1 \mathrm{MPam}^{1 / 2}$. The variation of the displacement in radial distance $r=3$ and $5 \mathrm{~mm}$ is caused by the various boundary conditions. 


\subsection{Results obtained by ODM}

The above-mentioned source of nodal displacement field was generated by FEM (using the ANSYS solution tools). For every $\alpha$ ratio and every half-ring distance the set of coefficients of WE were calculated. In total 51 points from FEM allows to calculate 50 coefficients of $A_{\mathrm{n}}$. For faster calculation with sufficient precision, the calculation was limited up to the first 20 coefficients. The first five WE coefficients(see, eq. (1)) for $\alpha=0.1, \alpha=0.3$ and $\alpha=0.8$ are mentioned in Tab. 3 for various radial distance $r=1$; $3 ; 5 \mathrm{~mm}$. Note that, stress field in the vicinity of the crack tip is described analytically usually by $\operatorname{SIF}\left(K_{\mathrm{I}}=\sqrt{2} \pi \times A_{1}\right)$ and $\mathrm{T}$-stress $\left(T=4 \times A_{2}\right)$.

Tab. 3: Initial first five WE coefficients calculated via ODM for selected relative crack length and studied distance from crack tip at $r=1 \mathrm{~mm}$.

\begin{tabular}{|c|c|c|c|}
\hline & \multicolumn{3}{|c|}{$\boldsymbol{r}=\mathbf{1} \mathbf{~ m m}$} \\
\hline $\boldsymbol{n}[-]$ & $\boldsymbol{a} / \boldsymbol{W}=\mathbf{0 . 1}$ & $\boldsymbol{a} / \boldsymbol{W}=\mathbf{0 . 3}$ & $\boldsymbol{a} / \boldsymbol{W}=\mathbf{0 . 8}$ \\
\hline 1 & 12.61445 & 12.61461 & 12.61505 \\
\hline 2 & -0.19515 & 0.181144 & 0.467172 \\
\hline 3 & -0.05358 & -0.11717 & -0.50842 \\
\hline 4 & 0.005094 & 0.001388 & 0.020191 \\
\hline 5 & -0.00295 & -0.00074 & -0.00886 \\
\hline
\end{tabular}

Tab. 4: Initial first five WE coefficients calculated via ODM for selected relative crack length and studied distance from crack tip at $r=3 \mathrm{~mm}$.

\begin{tabular}{|c|c|c|c|}
\hline & \multicolumn{3}{|c|}{$\boldsymbol{r}=\mathbf{3} \mathbf{~ m m}$} \\
\hline $\boldsymbol{n}[-]$ & $\boldsymbol{a} / \boldsymbol{W}=\mathbf{0 . 1}$ & $\boldsymbol{a} / \boldsymbol{W}=\mathbf{0 . 3}$ & $\boldsymbol{a} / \boldsymbol{W}=\mathbf{0 . 8}$ \\
\hline 1 & 12.61418 & 12.61443 & 12.61524 \\
\hline 2 & -0.19538 & 0.180936 & 0.467012 \\
\hline 3 & -0.05416 & -0.11773 & -0.50901 \\
\hline 4 & 0.005112 & 0.001342 & 0.020133 \\
\hline 5 & -0.00219 & 0.000061 & -0.00798 \\
\hline
\end{tabular}

Tab. 5: Initial first five WE coefficients calculated via ODM for selected relative crack length and studied distance from crack tip at $r=5 \mathrm{~mm}$.

\begin{tabular}{|c|c|c|c|}
\hline & \multicolumn{3}{|c|}{$\boldsymbol{r}=\mathbf{5} \mathbf{~ m m}$} \\
\hline $\boldsymbol{n}[-]$ & $\boldsymbol{a} / \boldsymbol{W}=\mathbf{0 . 1}$ & $\boldsymbol{a} / \boldsymbol{W}=\mathbf{0 . 3}$ & $\boldsymbol{a} / \boldsymbol{W}=\mathbf{0 . 8}$ \\
\hline 1 & 12.61421 & 12.61453 & 12.6157 \\
\hline 2 & -0.19544 & 0.180887 & 0.466981 \\
\hline 3 & -0.05428 & -0.11785 & -0.50912 \\
\hline 4 & 0.00511 & 0.001335 & 0.020123 \\
\hline 5 & -0.00213 & 0.000126 & -0.00791 \\
\hline
\end{tabular}

As it is seen in Tabs $3-5$, results obtained from ODM are in good agreement for fist WE coefficient $A_{1}$, which is related to $K_{\mathrm{I}}$ for all studied $\alpha$ ratios and radial distances $r$. The difference in all cases in $0.1 \%$. However, the higher WE coefficients calculated by ODM shows great mismatch with the demanded results. This fact is visible for values of $A_{2}$ coefficient calculated for $\alpha=0.1$ for all radial distances, where the $A_{2}$ should have positive values as presented in Tab. 2 .

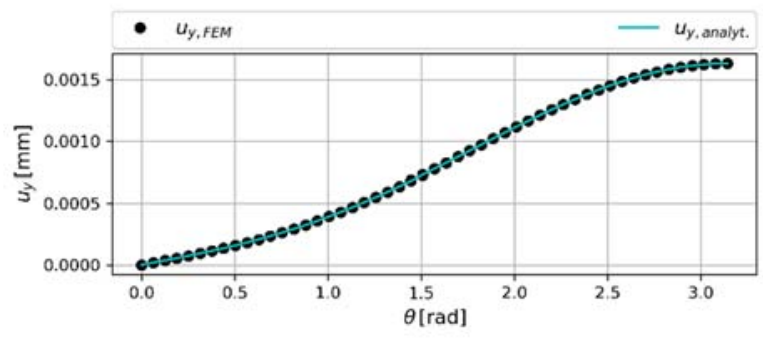

(a) $-r=1 \mathrm{~mm}, \alpha=0.1$

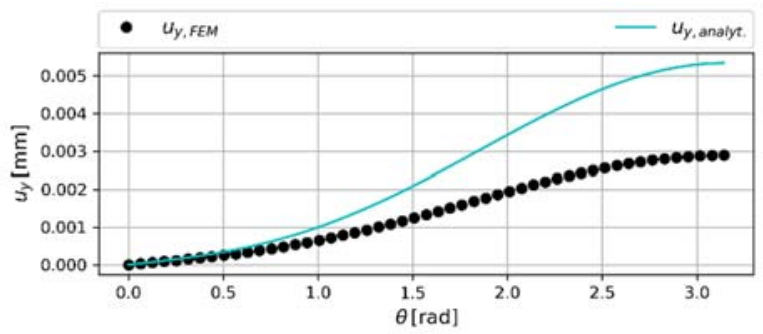

(b) $-r=3 \mathrm{~mm}, \alpha=0.1$

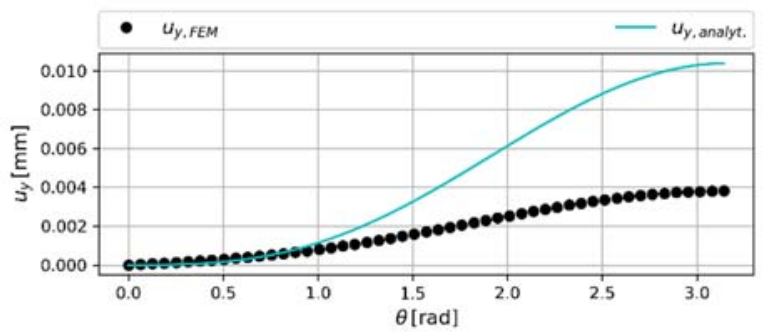

(c) $-r=5 \mathrm{~mm}, \alpha=0.1$

Fig. 6: Comparison of displacements obtained from analytical for first member and numerical solution (infinite number of terms) in radial distance from crack tip $r=1,3,5 \mathrm{~mm}$ and for $\alpha=0.1$.

Presented comparison of nodal and calculated displacements $u_{\mathrm{y}}$ for various radial distances are presented in Fig. 6. From Fig. 6(a) in can be noted that the differences in $u_{\mathrm{y}}$ are limited to tenth of percent. However, the difference in $u_{\mathrm{y}}$ calculated by FEM and ODM increases with increasing radial distance from the crack tip. This effect is greatly visible in Fig. 6(c) for $r=5 \mathrm{~mm}$. These disagreements are caused by lack of calculated coefficients of WE and authors recommend calculating more than 20 WE coefficients. This fact should be considered since the $u_{\mathrm{y}}$ displacement opens the crack in mode I deformation.

\section{Conclusion}

A calculation of higher order coefficients of Williams expansion by over-deterministic method was presented based on the input of nodal displacement calculated by finite element software. In the study, the calculated WE coefficients shows good agreement only for first member, which is directly related to $K_{\mathrm{I}}$. The disagreement in higher 
order terms is caused but choosing insufficient number of WE coefficients.

Determination of a particular number of terms that allows a sufficiently correct approximation of a displacement field in a real situation should therefore be supported by an analysis similar to that presented here with a possible additional convergence analysis

The results of this study may have significant implications for transfer of material properties from fracture and fatigue analyses of civil engineering materials applied in structures.

\section{Acknowledgements}

This paper presents results obtained within the project DS2016-0060, which belongs to Multilateral Scientific and Technological Cooperation Project in Danube Region between Technische Universität Wien, Brno University of Technology and University of Belgrade.

This paper has been worked out under the "National Sustainability Programme I" project "AdMaS UP Advanced Materials, Structures and Technologies" (No. LO1408) supported by the Ministry of Education, Youth and Sports of the Czech Republic and Brno University of Technology.

The second author is Brno Ph.D. Talent Scholarship Holder - Funded by the Brno City Municipality.

The fourth author would like to acknowledge the support of the project No. 7AMB187AT - Failure initiation and fracture of quasi-brittle building materials.

The fifth author would like to acknowledge the support of the AKTION Austria - Czech Republic within her visiting fellowship at the Brno University of Technology in 2017 dealing with the research project: Natural fibre concrete under biaxial load - advanced evaluation of experimental results using complex fracture mechanics methods.

\section{References}

[1] TSCHEGG, E.K. Republic Österreich. Patent number 390328B, 1986

[2] LINSBAUER, H.N. and E.K. TSCHEGG. Fracture energy determination of concrete with cube-shaped specimens. Zement und Beton, 1986, vol.31, pp. 3840.

[3] BRUHWILER, E. and F.H. WITTMANN. The wedge splitting test: a new method of performing fracture mechanics tests, Engineering Fracture Mechanics, 1990, vol.35, pp. 117-125. DOI: 10.1016/0013-7944(90)90189-N.

[4] ZIMMERMANN, T., and D. LEHKY. Fracture parameters of concrete C40/50 and C50/60 determined by experimental testing and numerical simulation via inverse analysis. International Journal of Fracture, 2015, vol. 192, pp. 179-189, DOI: 10.1007/s10704-015-9998-0.

[5] SEITL, S., I. MERTA, and V. VESELY. Wedge splitting test of foam concrete specimens: Calibration curves. Key Engineering Materials, 2015, vol. 627, pp. 281-284.

DOI: 10.4028/www.scientific.net/KEM.627.281.

[6] MERTA, I., and E.K. TSCHEGG. Fracture energy of natural fibre reinforced concrete. Construction and Building Materials, 2013, vol. 40, pp. 991-997. DOI: 10.1016/j.conbuildmat.2012.11.060

[7] R. WALTER, L. ØSTERGAARD, J.F. OLESEN and H. STANG. Wedge splitting test for a steel-concrete interface. Engineering Fracture Mechanics, 2005, vol. 72, pp. 2565-2583. DOI: 10.1016/j.engfracmech.2005.06.001.

[8] KORTE, S., V. BOEL, W. DE CORTE and G. DE SCHUTTER. Behaviour of fatigue loaded selfcompacting concrete compared to vibrated concrete. Structural Concrete, 2014, vol. 15(4), pp. 575-589. DOI: $10.1002 /$ suco.201300085.

[9] KORTE, S., V. BOEL, W. DE CORTE and G. DE SCHUTTER. Comparative study on the fatigue behaviour of SCC and VC. Key Engineering Materials., 2015, vol. 627, pp. 333-336. DOI: 10.4028/www.scientific.net/KEM.627.333.

[10] KORTE, S., V. BOEL, W. DE CORTE and G. DE SCHUTTER. Static and fatigue fracture mechanics properties of self-compacting concrete using threepoint bending tests and wedge-splitting tests. Construction and Building Materials., 2014, vol. 57, pp. 1-8. DOI: 10.1016/j.conbuildmat.2014.01.090.

[11] SEITL, S. T. THIENPONT and W. DE CORTE. Fatigue crack behaviour: comparing three-point bend test and wedge splitting test data on vibrated concrete using Paris' law. Frattura ed Integrità Strutturale, 2017, vol. 39 pp. 110-117; DOI: 10.3221/IGFESIS.39.12.

[12] ASTM E 1221-96, Standard Method for Determining Plane-Strain Crack-Arrest Toughness, $K_{\text {Ia }}$ of Ferritic Steels. American Society for Testing and Materials, Philadelphia, PA, 2002

[13] TSCHEGG, E.K., A. SCHNEEMAYER, I. MERTA and K. RIEDER. Energy dissipation capacity of fibre reinforce concrete under biaxial tension-compression load. Part I: Test equipment and work of fracture. Cement \& Concrete Composite, 2015, vol. 62, pp. 195-203. DOI: 10.1016/j.cemconcomp.2015.07.002.

[14] SEITL, S., Z. KNESL, V. VESELY and L. ROUTIL. A refined description of the crack tip stress field in wedge-splitting specimens-a two-parameter fracture mechanics approach. Applied and Computational 
Mechanics. 2009, vol. 3, iss. 2. ISSN 2336-1182.

[15] SOBEK, J. Shape functions analysis of cracked specimens: Plane problem variants. Sbornik vědeckých praci Vysoké školy báňské - Technické university Ostrava, číslo 1, 2014, článek č. 20 (in Czech)

[16] WILLIAMS, M.L. On the stress distribution at the base of a stationary crack, Journal of Applied Mechanics, 1975, vol. 24, pp. 109-114. ISSN 00218936.

[17] AYATOLLAHI, M.R. and M. NEJATI. An overdeterministic method for calculation of coefficients of crack tip asymptotic field from finite element analysis. Fatigue and Fracture of Engineering Materials and Structures, 2010, vol. 34, pp. 159-176. DOI: $10.1111 /$ j.1460-2695.2010.01504.x.

[18] VESELY, V., J. SOBEK, L. SESTAKOVA, P. FRANTIK and S. SEITL. Multi-parameter crack tip stress state description for estimation of fracture process zone extent in silicate composite WST specimens. Frattura ed Integrita Strutturale, 2013, vol. 7, iss. 25, pp. 69-78. DOI: 10.3221/IGFESIS.25.11

[19] RUZICKA, V., L. MALIKOVA and S. SEITL. Overdeterministic method: The influence of rounding numbers on the accuracy of the values of Williams' expansion terms. Frattura ed Integrità Strutturale. 2017, vol. 11, iss. 42, pp. 128-135. DOI: 10.3221/IGF-ESIS.42.14.

[20] SEITL, S., B. NIETO GARCÍA and I. MERTA. Wedge splitting test method: quantification of influence of glued marble plates by two-parameter fracture mechanics. Frattura ed Integtita Strutturale, 2014, vol. 30, pp. 174-181. DOI: 10.3221/IGFESIS.30.23.

[21] ANSYS® Release 17.2. Academic research, Crack analysis guide Mechanical APDL Documentation guide, 2016.

[22] SEITL, S., V. VESELY and L. ROUTIL. Twoparameter fracture mechanical analysis of a nearcrack-tip stress field in wedge splitting test specimens. Computers and Structures, 2011, vol. 89, $\mathrm{pp}$ $1852-1858$.

DOI: 10.1016/j.compstruc.2011.05.020.

[23] GUINEA, G.V., M. ELICES and J. PLANAS. Stress intensity factors for wedge-splitting geometry. International Journal of Fracture, 1996, vol. 81, pp. 113-124. DOI: 10.1007/BF00033177.

\section{About Authors}

Stanislav SEITL was born in Přerov, Czech Republic. He received his habilitation (Assoc. prof.) from FCE BUT in 2015. His research interests include numerical simulation, fatigue and failure analysis and fracture-mechanical properties of civil engineering materials.

Petr MIARKA was born in Český Těšín, Czech Republic. He received his M.Sc. from FCE BUT in 2017. His research interests include numerical simulation, fatigue and failure analysis and fracture-mechanical properties of civil engineering materials.

Vladimír RUZICKA was born in Přerov, Czech Republic. He received his M.Sc. from FIT BUT in 1999. His research interests include multiparameter linear elastic fracture mechanics analysis, support research by programing and evaluation of fracture-mechanical properties of civil engineering materials.

Lucie MALIKOVA was born in Štenberk Czech Republic. She received her Ph.D. from FME BUT in 2009. Her research interests include numerical simulation, fatigue and failure analysis and fracture-mechanical properties of civil engineering materials.

Ildiko MERTA was born in B. Topola (former Yugoslavia). She received her $\mathrm{PhD}$ from the TU WIEN in 2006. Her research interests include development, characterisation and optimisation of sustainable cementitious building materials. 